\title{
A MAGIA DAS IMAGENS TÉCNICAS E O DESAPARECIMENTO DO REAL - REFLEXÕES A PARTIR DA LEITURA DE VILÉM FLUSSER
}

\author{
THE MAGIC OF TECHNICAL IMAGES AND THE DIS APPEARANCE OF THE REALITY - \\ REFLECTIONS FROM VILEM FLUSSER READING
}

\author{
ELIONAI ROBINSON - UNINTER ${ }^{1}$ \\ GUISELA KRAETZ - UNINTER ${ }^{2}$ \\ MARIO SERGIO CUNHA ALENCASTRO - UNINTER ${ }^{3}$
}

\begin{abstract}
RESUMO: Pretende-se neste artigo, um ensaio teórico, revisitar a obra de Vilém Flusser, em especial ao que tange ao advento das imagens técnicas, elementos produzidos por recursos proporcionados pelas tecnologias computacionais e da informação. Embora metaforicamente Flusser se refira principalmente à imagem fotográfica, sua abordagem pode muito bem ser aplicada para qualquer tipo de imagem produzida pela mediação técnica, inclusive as imagens digitais feitas por computador. Essas imagens técnicas materializam determinados conceitos a respeito do mundo, exatamente os conceitos que nortearam a construção dos aparelhos que lhes deram forma o que pode servir para uma espécie de "mascaramento da realidade". Em tempos de pós-verdades, das manipulações textuais e imagéticas amplamente divulgadas pela Internet e até por meios convencionais como a televisão, revisitar o arcabouço teórico que Flusser deixou como herança é de suma importância.
\end{abstract}

Palavras-chave: Vilém Flusser; Imagens técnicas; Pós-história; Simulacros.

\begin{abstract}
The aim of this paper, a theoretical essay, is to revisit the work of Vilém Flusser, especially regarding the advent of technical images, elements produced by resources provided by computational and information technologies. Although metaphorically Flusser refers primarily to photographic imaging, his approach may well apply to any kind of image produced by technical mediation, including digital computermade images. These technical images materialize certain concepts about the world, exactly the concepts that guided the construction of the apparatuses that shaped them, which can serve as a kind of "masking of reality". In times of post-truth, textual and imaginary manipulation widely circulated on the Internet and even by conventional means such as television, revisiting the theoretical framework that Flusser left as an inheritance is of paramount importance.
\end{abstract}

Key-words: Vilém Flusser; Technical images; Posthistory; Simulacrum.

\section{INTRODUÇÃO}

Um relato muito interessante e que serve como motivação para o assunto que será tratado neste pequeno ensaio, é apresentado por Casti (1998, p. 46-47). Trata-se da história de Chris

\footnotetext{
${ }^{1}$ Discente do Mestrado Profissional em Educação e Novas Tecnologias do Centro Universitário Internacional Uninter.

2 Discente do Mestrado Profissional em Educação e Novas Tecnologias do Centro Universitário Internacional Uninter.

${ }^{3}$ Professor do Mestrado Profissional em Educação e Novas Tecnologias do Centro Universitário Internacional Uninter.
} 
Langton, que, no ano de 1975, quase morreu num acidente de asa delta numa montanha da Carolina do Norte (EUA). Durante os longos meses de sua convalescença, Langton mergulhou na pesquisa do que mais tarde seria chamado de vida artificial. Sua convicção era que, em relação aos organismos vivos, tudo o que existisse poderia ser criado no interior confortável de um computador. Uma vida “em silício" em oposição à vida in vito. A seqüência da história já é por demais conhecida e as pesquisas nos campos da computação, relacionadas com as "realidades virtuais" cresce a cada dia.

Hoje, a distância que separa a observação passiva dos "mundos virtuais" para sua experimentação ativa é muito pequena. Para Casti, "embora a ideia de vestir um capacete de vídeo e luvas de dados e entrar na imagem da Liga Nacional de Futebol possa parecer inimaginável" muitos aficionados da realidade virtual encaram isso como uma das "possibilidades mínimas do que pode acontecer” (1998, p. 45). Segundo ele, um bom exemplo dessa participação ativa, pode ser encontrado nas máquinas simuladoras de vôo, onde pilotos comerciais e militares conseguem aprimorar suas habilidades técnicas e comportamentais.

Uma das discussões mais interessantes no campo dos novos meios de comunicação, dos computadores e das tecnologias da informação, diz respeito ao relacionamento da chamada realidade virtual com o mundo real. Como os mundos virtuais se relacionam com seus correspondentes do mundo real? Até que ponto as novas tecnologias estariam subtraindo a dimensão real (concreta) dos fatos e acontecimentos? Que tipos de comportamentos podem emergir da interação desses dois mundos? Essas são apenas algumas das diversas questões que estão emergindo e que têm estimulado acalorados debates. Jean Baudrillard, por exemplo, coloca o problema nos seguintes termos: "no passado esperava-se que o virtual virasse real - a realidade era a sua destinação. Hoje a função do virtual é proscrever o real. A História virtual está ocupando o lugar da História real; a informação-réplica representa e provoca a ausência definitiva daquela Histórica real” (2001, p. 56-57). Tudo conduz a uma discussão que, embora cada vez mais freqüente nos círculos dos pensadores que discutem a modernidade, tem gerado muitas controvérsias, está longe de ser equacionada e até mesmo compreendida com clareza.

Pretende-se com este artigo, um ensaio teórico, chamar a atenção dos pesquisadores para a importância dessa discussão. Para tanto, será utilizado o trabalho do pensador tcheco Vilém Flusser, que viveu 31 anos no Brasil, e realizou uma das mais vigorosas críticas sobre a influência dos dispositivos e processos tecnológicos na vida humana. Em meados dos anos 80, Flusser publicou a obra Filosofia da Caixa Preta, na qual faz uma profunda reflexão sobre as possibilidades de criação e liberdade numa sociedade cada vez mais marcada pelo tecnocentrismo (MACHADO, 2001, p. 37). 
Nesta obra, ele dirige suas reflexões para as chamadas "imagens técnicas", produzidas de forma mais ou menos programática através da mediação de aparelhos de codificação. Embora se refira principalmente à imagem fotográfica, sua abordagem pode muito bem ser aplicada para qualquer tipo de imagem produzida pela mediação técnica, inclusive as imagens digitais feitas por computador. Essas imagens técnicas materializam determinados conceitos a respeito do mundo, exatamente os conceitos que nortearam a construção dos aparelhos que lhes deram forma o que pode servir para uma espécie de "mascaramento da realidade".

\section{A PÓS-HISTÓRIA}

O estudo da obra de Flusser é de suma importância, pois, ao introduzir seu conceito de Pós-história, aborda a questão da formação social contemporânea de forma bem diferente do que tem sido feito até agora. Para comentadores de sua obra, como Srtröhl (2000, p. 54), enquanto muitos teóricos anunciaram o advento de uma nova formação social, que denominaram de "pósmodernidade", na qual a comunicação eletrônica se torna a forma predominante de comunicação social, e que traz em seu bojo um sem número de conseqüências, tais como crise dos valores tradicionais, barbárie cultural, consumismo vazio de significados, etc., Flusser via as coisas de um modo um tanto quanto diferente.

Grosso modo, muitos pensadores da pós-modernidade viam os meios de comunicação de massa como parte da paisagem social moderna. Esses meios de comunicação penetram em todas as esferas da vida social, profissional, religiosa, no lazer, na educação, na participação política, enfim, em todos os campos da atividade humana. Tais meios de comunicação não só transmitem mensagens, como também difundem e definem padrões de comportamento com uma eficiência jamais obtida antes. Pode-se dizer que tudo o que é produzido pelo sistema industrializado de produção cultural (TV, rádio, jornal, revistas, etc) é elaborado de forma a influenciar, aumentar o consumo e transformar hábitos.

Não há dúvida de que a indústria da cultura, centrada nesses meios de comunicação de massa, é um elemento muito importante das sociedades modernas. Trata-se de um processo de manipulação das consciências a partir de um grande aparato tecnológico construído em moldes industriais que subtrai dos indivíduos suas percepções. A ideologia não é mais passada como um conjunto de ideias, mas como a organização do mundo, feita a partir de uma razão objetivamente determinada. Vive-se numa sociedade ficcional, na qual o cotidiano e a realidade se aproximam de ficções. O cinema sonoro, por exemplo, reproduz o mundo "tal qual ele é", manipulando a percepção que as pessoas têm das coisas. A platéia sai do espetáculo comentando a vida e os 
problemas dos personagens, como se fossem reais, vivenciando as experiências dos personagens objetivamente determinadas pela indústria cultural - "copiando-as" e deixando de lado suas próprias experiências e percepções.

Mas, se para Adorno, citado por Arantes (2000, p. 7), a técnica passa a exercer imenso poder sobre a sociedade, graças ao fato de que as circunstâncias que favorecem tal poder são arquitetadas pelo poder economicamente mais forte, identificando a racionalidade técnica à racionalidade do domínio econômico, Flusser vê na mudança de paradigmas, nos códigos com que as pessoas se comunicam como sendo a causa principal da Pós-história. O surgimento das imagens técnicas é a causa central de todos os efeitos descrito como Pós-histórico por ele e Pós-moderno pelos outros. "Num futuro moldado pela mídia, Flusser deduz um mundo de implicações políticas e culturais a partir de um punhado de estruturas básicas de comunicação" (SRTRÖHL, 2000, p. 59).

Um dos maiores problemas causados pela proliferação dessas imagens técnicas é o que Flusser (1998, p. 29) aponta como a predisposição da sociedade para um comportamento programado na qual já não mais se decifram as imagens como significados do mundo, mas o próprio mundo passa a ser vivenciado como um conjunto de imagens. Não mais sabendo servirse das imagens em função do mundo, o ser humano passa a viver em função das imagens. As imagens tradicionalmente encaradas como mapas se transformam em biombos, pois não mais representam e sim mascaram a realidade.

O próprio Flusser (1991, p. 286) usa a guerra do Golfo ${ }^{4}$ como exemplo desse mascaramento. Para ele, o conflito teria sido apresentado às massas sob a forma de um "jogo de computador", com a simulação de batalhas e de combates, com a impossibilidade de distinguir-se os objetos reais dos virtuais. Uma situação na qual a realidade estaria cada vez mais obscurecida pelas imagens técnicas. É interessante o fato de que, ao se referir a atual guerra no Iraque, iniciada há poucos dias, o filósofo francês Paul Virilio, afirma que "não há mais separação entre o campo de batalha real e o virtual" e que o "campo de percepção de uma guerra é mais importante do que o campo de batalha propriamente dito". A conquista do espaço virtual (on-line) é tão importante para os americanos do que a tomada do território iraquiano, pois o combate on-line acaba desembocando numa "sincronização de emoções" que conduz à perda do espírito crítico e, no momento seguinte, pode conduzir à idolatria (VIRILIO, 2003, p. A 24).

\footnotetext{
${ }^{4}$ Em agosto de 1990, o Iraque provoca um ataque contra o país vizinho Kuwait provocando assim um conflito internacional. A ONU, com o fracasso das negociações diplomáticas, autoriza um ataque militar ao Iraque, o que acontece em 16 de janeiro de 1991, quando forças coligadas de 30 países, liderados pelos EUA, iniciam uma série de bombardeios e uma grande ofensiva terrestre contra aquele país. Como conseqüência da ação militar, morreram aproximadamente 100 mil soldados e 7 mil civis iraquianos e 510 soldados das forças que compunham a coalizão. (ALMANAQUE Abril, 2001, p. 253).
} 
É o momento da Pós-história, ou, como bem disse Elias Canetti, citado por Baudrillard (2001, p. 68), “a partir de um certo ponto, a História não era mais real. Sem que se percebesse, toda a humanidade subitamente abandonou a realidade: tudo o que aconteceu desde então supostamente não foi verdadeiro". Como foi possível se chegar a este ponto? Uma abordagem genealógica tornase então necessária.

Nesse contexto, o termo "pós-verdade", um neologismo criado para descrever como a opinião pública é influenciada por algo que, com aparência de verdade, passa a ser mais importante do que a própria verdade, é de extrema atualidade. A pós-verdade, que se constrói a partir da superposição das versões em relação aos fatos em si, é notadamente presente nas propagandas políticas e em diversas formas de proselitismo ideológico (LLORENTE, 2017, p. 9).

\section{REVOLUÇÕES CULTURAIS}

Flusser (1998, p. 21) fala de duas revoluções fundamentais na estrutura cultural da humanidade. A primeira ocorreu aproximadamente em meados do segundo milênio a.C. quando aconteceu a “invenção da escrita linear". Neste ponto o ser humano teria passado de um estágio pré-histórico e mítico para uma fase histórica, lógica e baseada na escrita alfa-numérica. Para Flusser a invenção da escrita linear teria inaugurado uma espécie de "consciência histórica, consciência dirigida contra as imagens [até então hegemônicas] fato nitidamente observável entre os filósofos pré-socráticos ${ }^{5}$ e, sobretudo, entre os profetas judeus" (ibid., p. 28).

Segundo Flusser, a conseqüência desta primeira revolução foi uma espécie de supervalorização dos textos. Os textos, cujo propósito inicial seria uma mediação entre os homens e as imagens, uma ampliação do potencial comunicativo e cognitivo da humanidade, poderia tê-la conduzido - usando a terminologia adotada por Flusser - a uma espécie de "textolatria", na qual o homem "passa a viver, já não mais se servir dos textos, mas em função destes” (1998, p. 31).

\footnotetext{
${ }^{5} \mathrm{O}$ melhor exemplo desta primeira revolução talvez possa ser encontrado na Grécia Clássica dos séculos V e IV a.C., quando a cultura oral, de língua falada, predominante na região do mar Mediterrâneo foi sobrepujada pela ampla difusão da escrita. Foram necessárias apenas duas gerações, cerca de cinqüenta a sessenta anos, para que esta cultura eminentemente oral alcançasse a difusão ampla de uma cultura escrita. Essa primeira "informatização da sociedade" ocorreu de modo totalmente consciente, pois havia o temor pela suas múltiplas conseqüências, muitas delas possivelmente negativas. A "informatização", naquela época, também foi discutida com vivacidade e não pôde ser detida. $\mathrm{Na}$ época, muitas figuras proeminentes testemunharam esse processo, e suas palavras deixam claro que já havia entre os contemporâneos uma grande consciência do caráter revolucionário do que tinham diante de si. Sócrates (469399 a.C.), por exemplo, ainda estava muito enraizado na cultura oral. Ao que se sabe, não escreveu uma só linha. Platão (427-347 a.C.), seu aluno, já escrevia, mas privilegiava os diálogos, preservando assim o procedimento dialogal de Sócrates, seu mestre. Aristóteles (384-322 a.C.), no entanto, já se utilizou da escrita e do livro de maneira muito óbvia, quase como hoje (Cf. RAUCH, 2001, p. 58-59).

${ }^{6}$ A textolatria, pelo seu enorme poder de transformação, foi acompanhada de muitos comentários críticos. Sócrates, no Fedro, defende a opinião de que a escrita levaria o homem a negligenciar o cultivo da memória, tornando-se sabedor de muitas coisas, mas perdendo as relações essenciais entre elas: seria uma espécie de doxosophoi (erudito de aparência), distante dos antigos sophoi (sábios). Platão argumentou que com a linguagem escrita seria muito maior o risco de interpretações equivocadas do que com a linguagem falada, já que quando se escreve não se conhece nem o leitor futuro
} 
A segunda revolução, que ocorre atualmente, talvez traga conseqüências ainda maiores do que a primeira, pois a ruptura ocasionada pela passagem de uma cultura escrita para uma outra, por assim dizer, de multimídia traz conseqüências cujo alcance ainda é difícil de avaliar, inaugurando um modo de ser ainda imprevisível. Flusser (1998, p. 21) atribui esta segunda revolução à "invenção das imagens técnicas", produzidas por aparelhos, na qual a escrita é construída com e por máquinas, essencialmente pela articulação de imagens, imagens que podem ser digitalizadas, multiplicadas ao infinito e passíveis de distribuição instantânea. São imagens que vão desde a fotografia em sua forma mais simples, àquelas produzidas por meios eletrônicos, construídas em "ícones conseguidos através de sistemas inteligentes de produção e informação" (LAURENTIZ, 1991, p. 112). Se "a fotografia conseguiu inserir a imagem na História” (SRTRÖHL, 2000, p. 60), por outro lado "interrompeu o fluxo da História" (ibid., p.60).

Para Flusser (1998, p.75-76) ao longo da História, os textos explicavam as imagens, desmistificando-as. Atualmente, são as imagens que ilustram os textos remitificando-os. Um artigo de jornal, por exemplo, é lido em função das fotos, como que através delas. Não é o artigo que explica a fotografia, mas a foto é que proporciona a "leitura" do texto, ilustrando-o. A foto de uma cena de guerra é uma imagem carregada de valores, "plena de deuses", pois é capaz de mostrar o que é bom e o que é mau. As crianças são boas, os tanques são maus, a cidade em chamas é o inferno, enquanto que os médicos de branco são anjos... Ao ler o artigo, o leitor coloca-se sob o fascínio mágico da fotografia, não quer a explicação do que realmente aconteceu, suas causas ou efeitos, pois a fotografia é auto-suficiente, é ela e não o artigo (texto) que transmite a realidade, ou melhor, passa a ser a própria realidade, pois as pessoas estão programadas para enxergar magicamente, através da magia das fotos.

\section{IMAGENS TÉCNICAS}

É somente com as imagens computadorizadas que o processo se "fecha por completo". Imagens digitalizadas, construídas artificialmente, facilmente alteráveis. São essas imagens em três dimensões, móveis e passíveis de uma multiplicação infinita que tornam a magia da fotografia muito mais poderosa. Percebe-se aqui um upgrade do fenômeno. Da foto comum às imagens computadorizadas ocorre um grande salto, principalmente no que diz respeito à facilidade de

nem a situação concreta de quem lê. As conseqüências temidas na época deveriam ter sido levadas a sério. Os pontos de crítica levantados por Sócrates e Platão mostraram-se procedentes. A perda do saber oral da tradição ocorreu muito mais rápida e drasticamente do que se temia. Apenas alguns fragmentos desse tesouro da humanidade foram registrados e preservados do esquecimento. Perdeu-se uma tradição rica e viva, destruíram-se bens culturais infindáveis (RAUCH, 2001, p. 58-59). 
manipulação, velocidade de distribuição e simulação da realidade. Para que seja possível compreender este salto, torna-se necessária, mais uma vez, a abordagem genealógica.

Ainda de acordo com Flusser (1991, p. 284-286), quando o alfabeto foi inventado (há 3500 anos) era um código elitista, acessível somente aos sacerdotes e membros das castas superiores. $\mathrm{Na}$ Antiguidade e Idade Média os verdadeiros detentores do poder eram os letrados. Eram eles que codificavam as leis, os decretos e os demais valores que orientavam a sociedade. Mais tarde, graças a invenção da imprensa e pela introdução da escola obrigatória em alguns países da Europa, o código das letras foi se tornando cada vez menos elitista. Ao mesmo tempo, porém, o código das cifras e os algoritmos matemáticos estavam ganhando força e se estabelecendo como o novo código hermético e elitista.

Flusser argumenta que no Renascimento os cientistas e técnicos recorrem cada vez mais às cifras e sempre menos às letras, pela capacidade que têm, de servir de suporte aos fenômenos da natureza, agora vistos como quantificáveis. "A natureza é indescritível, mas calculável” e "os algoritmos são formados segundo regras 'auto-generativas': evoluem segundo as necessidades do conhecimento" (1991, p. 283). Já no final do século XIX os verdadeiros detentores do poder são os iniciados nos códigos de cifras. São eles, os cientistas e técnicos, que governam o comportamento - inclusive dos supostos detentores do poder, os militares, políticos e industriais - que, secundariamente iletrados (só conhecem o código das letras) são incapazes de decifrar os modelos matemáticos que regem o mundo.

Um grande impulso estava para ser dado e sua descrição é fundamental para a continuidade do raciocínio aqui apresentado. Dada a complexidade cada vez maior dos cálculos matemáticos, cada vez mais necessários ao mundo tecno-científico que estava sendo construído, surgiram as máquinas calculadoras rápidas, destinadas a abreviar e facilitar os cálculos e a manipulação das cifras. A evolução das máquinas de calcular teve sua continuidade no desenvolvimento dos computadores. Para Flusser os computadores "podem recompor os processos, as linhas, as superfícies, os volumes e os volumes móveis que calcularam. E podem recompô-los em formas diferentes das que calcularam. Podem computar mundos alternativos. Embora isto não seja onipotência, parece-se com ela [...]" (1991, p. 286).

Com o computador, consolida-se definitivamente o caminho para as imagens técnicas e para a virtualidade. Para Flusser (ibid., p.286) “a massa está recaindo do nível das letras para o das imagens controladas pelas cifras (numericamente generadas). Nova forma de sociedade, e nova forma de consciência, estão emergindo graças ao abandono do código alfanumérico pelas cifras. Pós-história é isso". 
As imagens eletrônicas difundidas pela televisão e, mais recentemente, as imagens digitais que trafegam no ciberespaço proporcionam uma distribuição e consumo de informações de uma forma excepcionalmente rápida. Tudo acontece de forma muito rápida, numa relação espaço-tempo que não é humana, pois trata-se do tempo da televisão, do cinema, da Internet, etc., podendo alterar a percepção individual e até mesmo os sistemas de organização social. Baudrillard reforça este ponto de vista quando diz que "nada sobreviverá como idéia ou conceito. Não haverá sequer tempo suficiente para imaginar. Acontecimentos reais, sequer terão tempo para se realizar. Tudo será precedido de sua realização virtual"' (2000, p. 73).

Essa proliferação imensa de imagens técnicas resulta para Flusser numa "nova magia [que] é a ritualização de programas, visando programar os seus receptores para um comportamento mágico programado" (1998, p. 36). Se o propósito das imagens é "serem mapas do mundo, mas passam a ser biombos" (1998, p. 21) isso significa que o ser humano ao invés de se utilizar das imagens, passa a viver em função delas. O mundo passa a ser vivenciado como um conjunto de cenas. Para Flusser essa inversão da função das imagens cria uma idolatria, sendo que o idólatra é o que vive magicamente: sua realidade reflete as imagens...

Melo (1988, p. 61) segue linha de raciocínio semelhante quando busca em Baudrillard a metáfora da metafísica, da transcendência, para explicar o que está se passando. Trata-se da metafísica do código, a partir da qual o real emerge como efeito ou reflexo dos modelos que agora lhe dão origem. O controle cibernético, a transparência de todos os circuitos, as simulações, a retro-alimentação e os sistemas de estímulo-resposta, características das imagens técnicas reforçam esta metafísica das imagens.

As imagens técnicas remagiciaram a vida a partir do momento em que o ser humano já não sabe mais o motivo pelas quais elas existem. Ocorre a mimese e a imagem deixa de ser um instrumento de orientação no mundo e passa a ser o mundo, deixa de ser código e passa a ser a própria situação que deveria representar. Quando se perde a capacidade de interpretar as imagens vive-se num estado de alucinação. "O caráter não simbólico, objetivo das imagens técnicas faz com que seu observador as olhe como se fossem janelas, não imagens. O observador confia nas imagens técnicas tanto quanto confia nos seus próprios olhos" (FLUSSER, 1998, p. 34).

Quando Flusser falava de Pós-história significava que, se "no curso da História os textos explicavam as imagens, desmistificando-as. Doravante, as imagens ilustram os textos, remitificandoos” (1998, p.76). As imagens técnicas são imagens retocadas, fabricadas, virtualizadas. Quando se contempla uma imagem produzida por aparelhos não é o mundo que está sendo visto, mas determinados conceitos relativos ao mundo que são o "resultado de um processo de codificação icônica de determinados conceitos científicos" (1998, p. 14). 
Cabe agora descrever a ontologia do ser humano idólatra, aquele que enxerga apenas a realidade das imagens técnicas. Se, com o advento dos computadores, os iniciados em seus códigos tiveram seu poder aumentado já que "os códigos dos computadores permitem calcular o exercício do poder (por exemplo, calculam decisões e jogam xadrez, ou calculam previsões e projetos, por exemplo, cenários de guerras)" permitindo aos iniciados exercerem "as funções de poder por intermédio das ditas 'inteligências artificiais"” (FLUSSER, 1991, p. 286), paradoxalmente surge nas massas uma quase que total ignorância em relação aos aparelhos computacionais.

\section{UMA NOVA ONTOLOGIA}

Para Flusser o ser humano comum é cada vez mais um operador de rótulos, um apertador de botões, "funcionário" das máquinas - caixas pretas com as quais lida sem ter a menor ideia do que se passa dentro delas - lidando sempre com situações pré-programadas sem se dar conta que isso está acontecendo. Pensa que é livre, mas a sua liberdade e criatividade estão restritas a um software, um conjunto de possibilidades dadas a priori e que não domina completamente. Isso define seu modo de agir e pensar, explicando assim sua dependência em relação às imagens técnicas. Jean Chesneaux (1996, p. 113) parece reforçar o ponto de vista flusseriano quando diz que a programação modela a sucessão dos comportamentos humanos. Da automação do trabalho conseguiu atingir o campo do intelecto e do conhecimento. A programação é redutora, efetuando uma otimização dos procedimentos gestuais e mentais no formato da máquina, e também quando propõe sistemas simbólicos apropriados às capacidades da máquina. Nas palavras de Flusser, citado por Machado (2001, p. 42), "somos, por enquanto, analfabetos com relação às imagens técnicas. Não sabemos como decifrá-las". Essa ignorância ao que está "por trás" das imagens é a causa da robotização e da automatização dos comportamentos.

Haveria alguma saída para este labirinto? Baudrillard (2001, p. 71) alerta para o fato de que, quando se caminha para uma espécie de limite final, há sempre a possibilidade de se recorrer a hipóteses fantásticas tais como a dependência total da espécie humana perdida numa espécie de escrita automática do mundo, dedicando-se a uma realidade virtual automatizada e operacionalizada onde os seres humanos enquanto tais não têm mais motivos para existir. A subjetividade humana se transforma num conjunto de funções inúteis, sendo que as funções tradicionais - a crítica, a sexual e as funções sociais tornam-se inúteis num mundo virtual. 


\title{
CONSIDERAÇÕES FINAIS
}

$\mathrm{Na}$ busca de visões mais otimistas é inevitável recorrer-se ao velho Nietzsche. Para ele era possível ao artista arrancar o homem de seu estado letárgico e de alienação

\begin{abstract}
Somente ao artista é permitida aquela espécie de perversidade que é o experimentar [...] porque ele possui aquele 'pathos de distância' próprio da alma aristocrática, que não se permite a pergunta pela 'intenção', pelo 'para que fim?' de sua obra, que não quer afirmar sua verdade, mas sua beleza (não a beleza no sentido metafísico - o que é o belo?...), e que também não aceita um julgamento pelos critérios da intenção, ao contrário, ela mesma pede o divórcio do artista, como a criança em relação à mãe (apud. PASCHOAL, 1999, p. 146).
\end{abstract}

A arte seria um mecanismo muito importante para a superação e liberação do homem em relação aos seus condicionamentos. A valorização da arte e do instinto estético - o saber artístico - podem proporcionar condições de acesso às questões fundamentais da existência, uma alternativa à racionalidade moderna, possibilitando que a dimensão criativa do homem aflore com todo o vigor e energia necessários.

Flusser parece concordar com Nietzsche ao propor que é possível usar os programas congelados nas máquinas contra a intenção dos autores e usá-los, deliberadamente de forma imprópria. A arte pode (e deve) fazer uma tentativa de usar a tecnologia e aqueles conceitos materializados, de forma subversiva (SRTRÖHL, 2000, p. 71). Para Flusser, a arte e a filosofia devem se insurgir contra este triste estado de coisas. "Toda a crítica da imagem técnica - diz Flusser - deve visar ao branqueamento dessa caixa-preta". (apud MACHADO, 2001, p. 43). E conclui: "novamente aqui, a função de uma filosofia da fotografia é denunciar a idolatria moderna como uma forma de alucinação, contribuindo para o desvelamento, para o branqueamento da caixa-preta". (MACHADO, 2001, p. 138).

\section{REFERÊNCIAS}

ALMANAQUE Abril. Ano 27. Edição Mundo 2001. São Paulo: Editora Abril, 2001.

ARANTES, Paulo Eduardo. Adorno: vida e obra. In: Os Pensadores. São Paulo: Nova Cultural, 2000. p. 5-11.

BAUDRILLARD, Jean. A ilusão vital. Rio de Janeiro: Civilização Brasileira, 2001.

CASTI, John L. Mundos virtuais: como a simulação está mudando as fronteiras da ciência. Rio de Janeiro: Revan, 1998.

FLUSSER, Vilém. Êxodo das cifras. Temas em debate. Revista Brasileira de Filosofia. v. XXXIX, fasc. 164, p. 283-286, out/nov/dez, 1991. 
1998.

Ensaio sobre a fotografia: para uma filosofia da técnica. Lisboa: Relógio D’água Editores,

JAPIASSÚ, Hilton; MARCONDES, Danilo. Dicionário básico de filosofia. 2. ed. Rio de Janeiro: Jorge Zahar, 1991.

CHESNEAUX, Jean. Modernidade-Mundo: brave modern world. 2.ed. Petrópolis: Editora Vozes, 1996.

LAURENTIZ, Paulo. A holarquia do pensamento artístico. São Paulo: Editora da UNICAMP, 1991.

LLORENTE, José Antônio. A era da pós-verdade: realidade versus percepção. Revista UNO, São Paulo, n 27, 2017.p. 9.

MACHADO, Arlindo. O quarto iconoclasmo. Rio de Janeiro: Marca d’Água, 2001.

A atualidade do pensamento de Flusser. In: BERNARDO, Gustavo ; MENDES, Ricardo.

(Orgs.). Vilém Flusser no Brasil. Rio de Janeiro: Relume Dumará, 2000. p. 131-143.

MELO, Hygina Bruzzi de. A cultura do simulacro: filosofia e modernidade em J. Baudrillard. São Paulo: Edição Loyola, 1988.

FERNANDES, Francisco; LUFT, Celso Pedro; GUIMARÃES, F. Marques. Dicionário Brasileiro Globo. 30. ed. São Paulo: Globo, 1993.

PASCHOAL, Antônio Edmilson. A dinâmica da vontade de poder como proposição moral nos escritos de Nietzsche. Campinas, 1999. 259 p. Tese de Doutorado, Universidade Estadual de Campinas.

RAUCH, Wolf. Ética da informação: o problema sob a ótica da ciência da informação. In: KOLB, Anton; ESTERBAUER, Reinhold; RUCKENBAUER, Hans-Walter. (Orgs.). Ciberética: responsabilidade em um mundo interligado pela rede digital. São Paulo: Loyola, 2001. p. 57-64.

SRTRÖHL, Andréas. Flusser como pensador europeu. In: BERNARDO, Gustavo ; MENDES, Ricardo. (Orgs.). Vilém Flusser no Brasil. Rio de Janeiro: Relume Dumará, 2000. p. 45-80.

VIRILIO, Paul. Inimigo: inventado pela propaganda. Folha de São Paulo, São Paulo, 06, abr., 2003, Folha Mundo, p. A 24. 